\title{
A Stochastic Investigation of Solar Energy Application Potential in Rural Households of Kenya and the Associated Environmental Benefits
}

\author{
Samwel N. Marigi \\ Institute for Meteorological Training and Research, Nairobi, Kenya \\ Email: drsmarigi@gmail.com
}

How to cite this paper: Marigi, S.N. (2017) A Stochastic Investigation of Solar Energy Application Potential in Rural Households of Kenya and the Associated Environmental Benefits. Journal of Geoscience and Environment Protection, 5, 1-11. https://doi.org/10.4236/gep.2017.54001

Received: March 8, 2017

Accepted: April 10, 2017

Published: April 13, 2017

Copyright $\odot 2017$ by author and Scientific Research Publishing Inc. This work is licensed under the Creative Commons Attribution International License (CC BY 4.0).

http://creativecommons.org/licenses/by/4.0/ (c) (i) Open Access

\begin{abstract}
In this study, the potential of solar energy for use in rural households of Kenya has been investigated. The main objective was to determine the viability of the solar energy resource as an alternative energy source that would alleviate or minimize the myriad of environmental and health problems associated with biomass based fuels predominantly used in the households. The stochastic behavior of sunny and cloudy spells has been modeled using the theory of runs, Poisson probability density function of occurrence of the spells and the geometric distribution of the length of the spells. A major application of the spells analysis is in the prediction of extended sunny and cloudy durations, which forms a basis for planning the solar energy use strategies. Results have indicated that the potential is quite promising and that substantial wood fuel savings and $\mathrm{CO}_{2}$ reductions are envisaged. These translated to environmental conservation and reduced risks of exposures to health hazards associated with wood fuel use.
\end{abstract}

\section{Keywords}

Energy, Model, Spell, Runs, Environment

\section{Introduction}

Energy is one of the most fundamental needs for sustainable socio-economic development of any nation [1]. Over the years, Kenya has experienced a growing demand for energy for both domestic and industrial activities owing to the increasing population and diversification of economic activities. Hydroelectricity and petroleum are the major sources of energy for most industrial activities in 
the country. About $87 \%$ of the country's domestic energy demand is met by biomass, in particular wood fuel and agricultural/animal wastes. Wood fuel, however, provides $90 \%$ and $85 \%$ of rural and urban households' energy requirement respectively [2]. Demand for wood fuel has led to substantial deforestation and land degradation [3]. Further, biomass cooking on traditional stoves is a major source of concentrated air pollutants including respirable particulate matter, carbon monoxide, nitrogen oxides, benzene, formaldehyde and aromatics. In many African countries, these have been linked to respiratory and pulmonary disorders including lung cancer, pneumonia, complications associated with pregnancy and other serious burns as well as eye infection [4] [5]. Abundance of indoor pests such as flies, termites, mosquitoes and rodents in rural homes is also related to the collection, storage and combustion of wood fuel as well as waste disposal. These pests may be vectors of human and other animals diseases.

It is, therefore, apparent that the health, deforestation and environmental degradation risks associated with biomass energy based cooking are becoming increasingly clear. This necessitates the search for efficient and appropriate technologies utilizing renewable sources of energy to reduce the demand on the fast depleting wood fuel resource and restore the ecological balance. Solar energy promises to be the fuel for tomorrow because of its multifaceted advantages. There are no emissions of gaseous pollutants or solid waste deposits from decentralised small units like solar cookers, solar water heaters and photovoltaics. Solar cookers are also labour saving, health saving and sometimes life-saving.

This paper, therefore, investigates the potential of solar energy for use in rural households of Kenya. One of the key issues in any solar energy utilization is the duration (in days) of continuous solar energy availability in any given season. The stochastic behaviour of sunny spells (periods of continuous solar energy availability) and cloudy spells (periods of continuous solar energy deficits) is modelled using the theory of runs, Poisson probability density function of occurrence of the spells and the Geometric distribution of the length of the spells. A major application of the spells analysis is in the prediction of extended sunny and cloudy durations which forms a basis for planning the solar energy use strategies. The spells also form a basis for evaluating wood fuel savings and hence environmental conservation as well as health hazards reduction in rural homes of the country.

\section{Justification of This Study}

Spatial and Temporal characteristics of global solar radiation have been examined in Kenya [6] [7]. By applying relatively simple techniques, these researchers have presented mean monthly values of global radiation which have revealed that north-western Kenya has the highest solar energy potential. The area maintains high radiation values throughout the year even during the month of July, a month with the largest values of cloud cover and lowest radiation values over many parts of the country.

However, the practical use of any solar energy system will require knowledge 
of the expected number of hours (duration) of continuous solar energy availability in any given day and season. This forms the fundamental basis of this study.

\section{Objective of This Study}

The main objective of this study was to determine the viability of the solar energy resource as an alternative energy source that would alleviate or minimize the environmental and health problems associated with the use of biomass based fuels in rural households of Kenya. Specific objectives were:

1. To determine the stochastic characteristics of sunny and cloudy spells for the four standard seasons experienced in the country.

2. To provide an illustration on quantified environmental benefits likely to be achieved from the applications of the spells in (1) above with regard to rural household energy use.

\section{Data and Methodology}

\subsection{Data}

Three global solar radiation measuring stations representing the high, moderate and low solar energy potential regions of Kenya have been chosen for analysis. These stations, Lodwar, Mombasa and Nyeri (Figure 1) possess daily global solar radiation data for the period $1975-2015$. Lodwar station $\left(3.11^{\circ} \mathrm{N}\right.$ and $\left.35.61^{\circ} \mathrm{E}\right)$ is located in the Arid and Semi-Arid Lands (ASALs). The area is characterized by a dry and hot climate as well as unreliable rainfall pattern ranging between $150 \mathrm{~mm}$ and $400 \mathrm{~mm}$ per annum. It experiences very high temperatures during the day and moderate temperatures during the night all year round. The temperatures range between $25^{\circ} \mathrm{C}-35^{\circ} \mathrm{C}$ all the year round. Mombasa station $\left(4.03^{\circ} \mathrm{S}\right.$ and $39.61^{\circ} \mathrm{E}$ ) is located within the coastal region and represents areas close to large water bodies. The area experiences a warm, tropical climate. The amount of rainfall depends essentially on season. The rainiest months are April and May, while in January to February the rainfall is minimal. Total annual rainfall averages $1072.7 \mathrm{~mm}$. The annual mean temperature is $26.3^{\circ} \mathrm{C}$. Nyeri station $\left(0.40^{\circ} \mathrm{S}\right.$ and $36.97^{\circ} \mathrm{E}$ ) on the other hand is located within the highland areas of the country. The area experiences equatorial rainfall due to its location within the equatorial highland zone of Kenya. The long rains occur from March to May while the short rains come in October to December, but occasionally this pattern is disrupted by abrupt and adverse changes in climatic conditions. The annual rainfall ranges between $500 \mathrm{~mm}-1600 \mathrm{~mm}$ depending on the season. Monthly mean temperatures in this area range from $12.8^{\circ} \mathrm{C}-20.8^{\circ} \mathrm{C}$.

The global radiation dataset for these three locations was obtained from the Kenya Meteorological Department Headquarters in Nairobi.

\subsection{Methodology}

Cloudiness is one of the major Meteorological parameters controlling radiation received at the surface. For purposes of this study, therefore, a day has been defined as being either cloudy or sunny based on the total radiation received and 


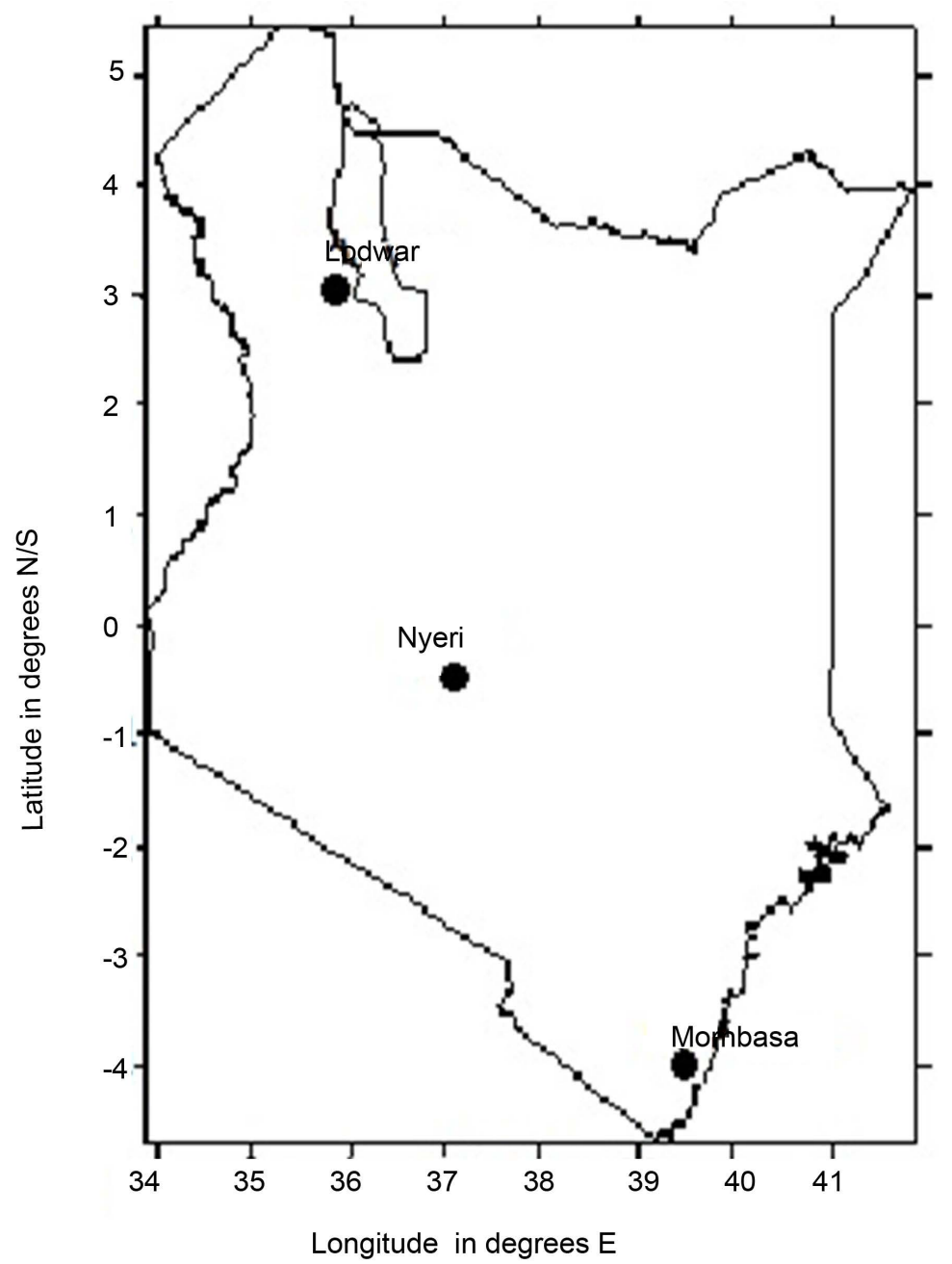

Figure 1. Global radiation stations used for sunny and cloudy spells study in Kenya.

some reference threshold radiation value. If $\mathrm{T}$ is the reference threshold radiation value and $\mathrm{X}$ the total radiation received in a given day, then $\mathrm{X}<\mathrm{T}$ represents a cloudy day and $\mathrm{X} \geq \mathrm{T}$ represents a sunny day. A threshold daily global radiation value of $5.4 \mathrm{Kwh} / \mathrm{m}^{2}$ has been used to define a day as being either sunny or cloudy. This value corresponds to the minimum daily global solar radiation requirement for moderate temperature activities performed in many rural households [8] [9].

The sequence of sunny or cloudy days may follow some trend of persistence or may evolve randomly. In stochastic theory, persistence may be represented by a Markov process of order one in which today's state is dependent only up to one day behind. A process displaying insignificant dependence is termed random or independent. Regardless of whether the process is Random or Markov, a sunny or cloudy duration (spell) may extend to a long period (days). Such periods (days) of several long spells are of crucial importance in planning solar energy use strategies.

An important step towards the prediction of extended sunny and cloudy spells for any season was then to quantify the structure of dependence (Markovian or 
Random) in the occurrence of sunny and cloudy days. This was accomplished by use of lag one serial correlation coefficient in the radiation series. Values of the coefficient were computed for the four standard seasons in each year considered. The significance of the correlation coefficient was tested by a Student's t-test.

\subsubsection{Model Formulation}

Let a sunny day be designated as " $s$ " and a cloudy day as " $c$ ". The conditional probability of any day being sunny given the previous day was also sunny is designated as $p(s / s)$ and the same connotation may be applied to a cloudy day followed by the previous cloudy day i.e. $p(c / c)$. For a random process, the conditional probability $p(s / s)$ equals the simple probability of any day being sunny, $p(s)$. For a Markov order one process, $\boldsymbol{p}(s / s) \neq \boldsymbol{p}(s)$. The following notations have been used in this paper: $p(s)=p$ and $p(s / s)=p p$.

If a time series of daily radiation $(\mathrm{X})$ during a season is plotted, events of uninterrupted sunny $(X \geq T)$ and cloudy $X<T$ will emerge along the time axis. The uninterrupted sunny or cloudy events are referred to as "runs". In a season of $n$ days, there will occur runs of sunny and cloudy days. The number of sunny runs is designated as $N_{s} N_{s}$ is given values $0,1,2, \cdots, i$. A sunny spell shall last for $\mathrm{L}_{\mathrm{s}}$ days and such duration of a spell is called the length of a run or spell. $L_{s}$ shall take on values $0,1,2, \cdots, j$. For planning and optimum utilization of solar energy, such spells as well as the longest spell are of crucial importance in planning the solar energy use strategies. The spell that has the longest $L_{s}$ will be designated as $L_{s m \text {. }}$

The probability density function (pdf) of occurrences of sunny spells may be regarded as following the Poisson distribution [10] while the distribution of the length of a run can be regarded as following the geometric pdf [11]. The mathematical expressions for these processes under Markovian dependence can therefore be written as follows:

$$
\begin{aligned}
& p\left(N_{s}=i\right)=\frac{[n p(1-p p)]^{i} \exp [-n p(1-p p)]}{i !} \\
& p\left(L_{s} \leq j\right)=1-p p^{j-1} \text { or } p\left(L_{s}>j\right)=p p^{j-1}
\end{aligned}
$$

where $n$ is the sample size.

The longest period of sunny spells can be deduced by applying the theorem of extremes of random numbers [12]. Using this theorem, the relationship for $L_{s m}$ in terms of probabilities can be written as:

$$
p\left(L_{s m} \leq j\right)=p\left(N_{s}=0\right)+\sum_{i=1}^{\infty} p\left(L_{s} \leq j\right)^{i} p\left(N_{s}=i\right)
$$

Sen [13] has derived the following relationships for the expected values of $N_{s}$ and $L_{s}$ denoted by $E\left(N_{s}\right)$ and $E\left(L_{s}\right)$ respectively for Markovian runs:

$$
\begin{aligned}
& E\left(N_{s}\right)=n p(1-p p) \\
& E\left(L_{s}\right)=1 /(1-p p) .
\end{aligned}
$$

The mathematical simplification of Equation (3) involving Equations (1) and 
(2) leads to the following:

$$
\begin{array}{r}
p\left(L_{s m} \leq j\right)=\exp \left[-n p(1-p p)_{*} p\left(L_{s}>j\right)\right] \\
p\left(L_{s m} \leq j\right)=\exp \left[-n p(1-p p)_{*} p p^{j-1}\right] \\
\text { since: } p\left(L_{s m}=j\right)=p\left(L_{s m} \leq j+1\right)-p\left(L_{s m} \leq j\right) .
\end{array}
$$

Hence:

$$
p\left(L_{s m}=j\right)=\exp \left[-n p(1-p p) p p^{j-1}\right]\left[\exp \left\{n p(1-p p)^{2} p p^{j-1}\right\}-1\right] .
$$

The expected value of the longest duration $E\left(L_{s m}\right)$ can be obtained from the relationship:

$$
E\left(L_{s m}\right)=\sum_{j=1}^{n} j p\left(L_{s m}=j\right) .
$$

In the context of Equations (1) through (10), the following need mentioning:

1) That for an independent or random process, the relationships remain the same except $p p$ is replaced by $p$.

2) That for a cloudy day, the relationships remain the same except $p$ is replaced by $q, p p$ by $q q, N_{s}$ by $N_{c}$ and $L_{s m}$ by $L_{c m}$

\subsubsection{Data Analysis}

In order to implement Equations (1)-(10), values of $p, p p, q$ and $q q$ are required. These were approximated by estimates of relative frequencies of the data sets for each year. Since there are $N$ years ( $N=41$ for each station), $N$ values of the aforesaid probabilities were obtained by a simple counting procedure. Finally, the values of $p, p p, q$ and $q q$ were ranked for each season and the median value substituted in equations 1 - 10 to generate the seasonal statistics.

\subsubsection{Quantification of the Likely Environmental Benefits}

Using this classical Chemical equation: $\mathrm{CH}_{2}+3 / 2 \mathrm{O}_{2} \rightarrow \mathrm{CO}_{2}+\mathrm{H}_{2} \mathrm{O}$, the following sequence illustrates how the benefits were computed:

1) Assume a typical family's firewood consumption is $\mathbf{X}$ Kilograms per day.

2) $\mathbf{X}$ Kilograms of firewood when burnt would generate $\mathrm{Y}$ Kilograms of $\mathrm{CO}_{2}$.

3) 1 Kilogram of firewood when burnt would therefore, generate $\mathrm{Y} / \mathrm{X}$ Kilograms of $\mathrm{CO}_{2}$.

4) In a season of $\mathbf{Z}$ days, a typical family consumes $\mathbf{Z X}$ Kilograms of firewood which translate to $\mathrm{Z} Y$ Kilograms of $\mathrm{CO}_{2}$ pollution.

5) Assuming a sunny spell of $L$ days and that solar energy will be the only alternative source of energy for the firewood, then the percentage firewood saving will be $(\mathrm{L} / \mathrm{Z})_{*} 100$. Similarly the percentage of $\mathrm{CO}_{2}$ reduction will be $(\mathrm{L} / \mathrm{Z}) * 100$.

\section{Results and Discussions}

\subsection{Model Simulation Results}

Applying the Student's T-test, a significant correlation coefficient assumes a value of at least 0.21 at $5 \%$ level of significance for each of the four standard seasons, each of which is three months length ( $n \approx 90$ days). Results obtained are 
tabulated in Table 1.

From the table, it is evident that at 5\% level of significance, occurrence of sunny and cloudy days can be regarded as following a Markov process because in more than $50 \%$ cases, the computed value of the correlation coefficient exceeded the critical value.

The levels of persistence in the spells in Lodwar and Mombasa were found strongly Markov whereas in Nyeri, they tended to be random in 50\% cases during the June-August season. The correlation coefficient does not seem powerful enough to dictate whether one should proceed with Markov or random modelling for Nyeri for this particular season. To clarify the anomaly, the Cumulative Distribution Function (CDF) of the sunny and cloudy spells was predicted using Equations (1)-(10) with the parameters of the Markov model as well as those of the random model. The predicted and observed CDFs are presented in Figure 2 and Figure 3.

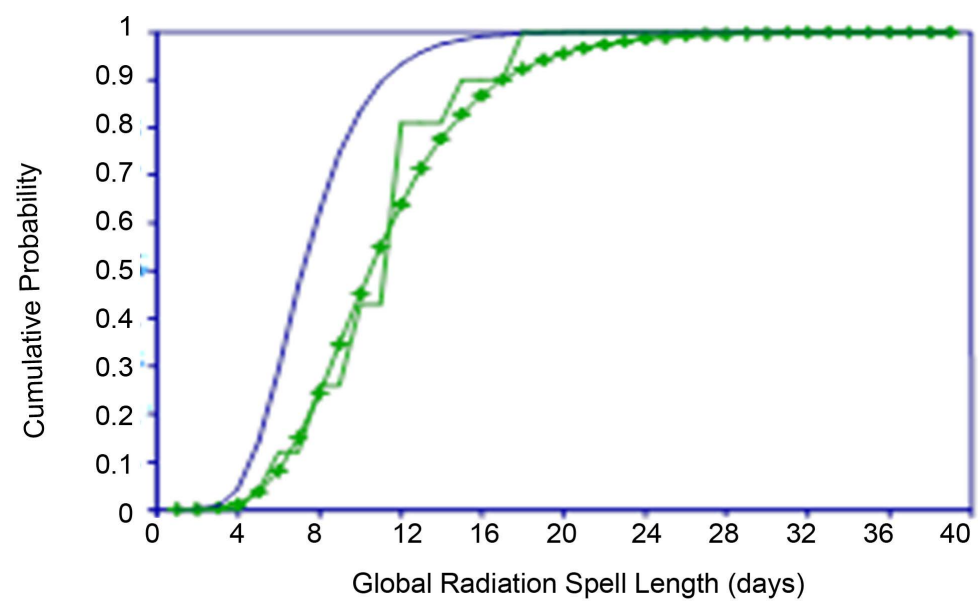

$\rightarrow$ Markov $\quad$ Random $\quad$ Observed

Figure 2. CDF of critical sunny spells in Nyeri during June-August season.

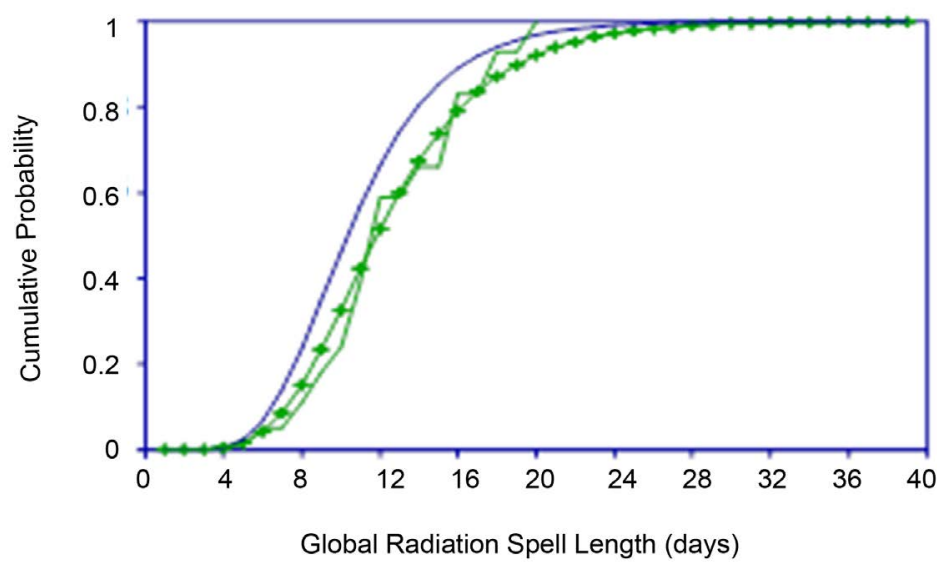

$\rightarrow$ Markov - Random - Observed

Figure 3. CDF of critical cloudy spells in Nyeri during June-August season. 
Table 1. Spells characteristics as inferred from lag one serial correlation coefficient.

\begin{tabular}{ccccccccc}
\hline Location & \multicolumn{2}{c}{ Dec.-Feb. Season } & \multicolumn{2}{c}{ March-May Season } & June-August Season & \multicolumn{2}{c}{ Sept.-Nov. Season } \\
& Markov & Random & Markov & Random & Markov & Random & Markov & Random \\
Lodwar & $95 \%$ & $5 \%$ & $100 \%$ & $0 \%$ & $83 \%$ & $17 \%$ & $92 \%$ & $8 \%$ \\
Nyeri & $100 \%$ & $0 \%$ & $79 \%$ & $21 \%$ & $50 \%$ & $50 \%$ & $83 \%$ & $17 \%$ \\
Mombasa & $83 \%$ & $17 \%$ & $100 \%$ & $0 \%$ & $92 \%$ & $8 \%$ & $100 \%$ & $0 \%$ \\
\hline
\end{tabular}

Figure 2 and Figure 3 depict the remarkable performance of the Markov model in simulating the observed behavior of the spells. It is also observed from the figures that the random model generally underestimates the observed behavior. Occurrence of sunny and cloudy days in Kenya can therefore be regarded as following a Markov process. Some statistics of the sunny and cloudy spells for each season and region were therefore computed using the Markovian expressions already given in Section 4.2.1. The statistics computed include the expected spell lengths ( $L_{s}$ and $L_{c}$ in days) as well as the expected length of the longest spell ( $L_{s m}$ and $L_{c m}$ in days). These statistics are presented in Table 2.

From Table 2, it is evident that the statistics are season and region dependent. However, the longest sunny spells are experienced in the December-February season while the shortest sunny spells are observed in the June-August season. In the moderate and low solar energy potential areas represented by Mombasa and Nyeri respectively, expected sunny spell lengths $\left(L_{s}\right)$ never exceed 7 days in all the seasons while in all the regions, expected cloudy spell lengths $\left(L_{c}\right)$ never exceed 4 days in all seasons apart from Nyeri where a cloudy spell would assume a value of 13 days in June-August season. In Lodwar, (a high potential area), sunny spells are generally long all the year round. The expected longest sunny spell $\left(L_{s m}\right)$ in this location ranges between 27 days and 47 days in all seasons while the expected longest cloudy spell $\left(L_{c m}\right)$ assumes durations of between 2 days and 5 days. In Nyeri, the expected longest sunny spell $\left(L_{s m}\right)$ takes values of between 3 days and 14 days in all seasons while the expected longest cloudy spell $\left(L_{c m}\right)$ assumes durations of between 5 days and 29 days. In Mombasa, the expected longest sunny spell $\left(L_{s m}\right)$ takes values of between 4 days and 20 days in all seasons while the expected longest cloudy spell $\left(L_{c m}\right)$ assumes durations of between 3 days and 13 days.

In solar energy applications, given the threshold radiation value, the expected sunny spell length $\left(L_{s}\right)$ represents the optimum duration (in days) a solar powered system can be put into use. The expected longest sunny spell $\left(L_{s m}\right)$ represents the maximum possible duration a solar powered system may be put into use. On the other hand, expected cloudy spell lengths $\left(L_{c}\right)$ as well as the expected longest cloudy spell $\left(L_{c m}\right)$ represent optimum durations and maximum possible durations respectively during which back-up systems or supplementary energy sources have to be used in a given season. Therefore in planning for solar energy use, all these parameters need to be taken into account. 
Table 2. Some statistics of sunny and cloudy spells in Kenya.

\begin{tabular}{ccccccccccccccccccc}
\hline Location & \multicolumn{1}{c}{ Dec.-Feb. Season } & \multicolumn{1}{c}{ March-May Season } & \multicolumn{1}{c}{ June-August Season } & \multicolumn{2}{c}{ Sept.-Nov. Season } \\
\hline & \multicolumn{1}{c}{ Sunny } & Cloudy & Sunny & Cloudy & Sunny & Cloudy & Sunny & Cloudy \\
& $L_{s}$ & $L_{s m}$ & $L_{c}$ & $L_{c m}$ & $L_{s}$ & $L_{s m}$ & $L_{c}$ & $L_{c m}$ & $L_{s}$ & $L_{s m}$ & $L_{c}$ & $L_{c m}$ & $L_{s}$ & $L_{s m}$ & $L_{c}$ & $L_{c m}$ \\
Lodwar & 40 & 47 & 1 & 2 & 36 & 41 & 4 & 3 & 19 & 27 & 3 & 5 & 33 & 37 & 2 & 2 \\
Nyeri & 4 & 14 & 2 & 5 & 3 & 7 & 4 & 11 & 2 & 3 & 13 & 29 & 2 & 7 & 3 & 9 \\
Mombasa & 7 & 20 & 2 & 3 & 3 & 9 & 3 & 9 & 2 & 4 & 4 & 13 & 4 & 13 & 2 & 4 \\
\hline
\end{tabular}

\subsection{Quantified Likely Environmental Benefits}

We start with the fact that a typical family's firewood consumption is 4 tonnes per year which translates to about $11 \mathrm{~kg}$ per day [14]. This quantity of firewood, if burnt would generate $20.57 \mathrm{~kg}$ of $\mathrm{CO}_{2}$ (from the chemical equation $\mathrm{CH}_{2}+$ $3 / 2 \mathrm{O}_{2} \rightarrow \mathrm{CO}_{2}+\mathrm{H}_{2} \mathrm{O}, 1 \mathrm{Kg}$ of firewood generates $1.87 \mathrm{Kg}$ of $\mathrm{CO}_{2}$ ). In a season of about 90 days, a typical family consumes $990 \mathrm{~kg}$ of firewood which releases a total of $1851.3 \mathrm{Kg}$ of $\mathrm{CO}_{2}$ pollution.

By using the sunny spell lengths tabulated in Table 2, the percentages of firewood savings and $\mathrm{CO}_{2}$ reductions are evaluated based on the procedure presented in Section 4.2.3. The evaluation assumes that solar energy will be the only source of energy for cooking and performing any other related household activity that consumes firewood. The results obtained are presented in Table 3.

From Table 3, it is evident that substantial firewood savings and $\mathrm{CO}_{2}$ reductions are envisaged. It is revealed that in a single sunny spell, firewood savings and $\mathrm{CO}_{2}$ reductions range from $21 \%-52 \%$ in Lodwar, a high solar energy potential area. In, Mombasa, a moderate solar energy potential area, the values range from $2 \%-22 \%$ while in Nyeri, a generally low solar energy potential area, the values range from $2 \%-17 \%$. All these quantities translate to reduced forest destruction activities and improved environmental conservation. The quantities also translate to reduced risks of exposures to health hazards associated with firewood use such as Acute Respiratory Infections (ARI), eye infections and burns as well as diseases brought about by vectors associated with firewood, its storage and waste disposal among others.

\section{Conclusions and Recommendations}

\subsection{Conclusions}

This study has revealed that the solar energy resource is viable for use as an alternative energy source in rural households of Kenya. A Markov model has been found adequate in estimating sunny and cloudy spells in the country. Estimates of sunny and cloudy spells based on this model have therefore been provided for some locations in the high, moderate and low solar energy potential regions. These estimates are crucial in any planning for solar energy utilisation in the country.

Substantial firewood savings and $\mathrm{CO}_{2}$ reductions are envisaged. These trans- 
Table 3. Potential firewood savings and $\mathrm{CO}_{2}$ reductions in Kenya's rural households.

\begin{tabular}{ccccccccc}
\hline Location & \multicolumn{2}{c}{ Dec.-Feb. Season } & \multicolumn{2}{c}{ March-May Season } & \multicolumn{3}{c}{ June-August Season } & \multicolumn{3}{c}{ Sept.-Nov. Season } \\
\hline & $\begin{array}{c}\text { Optimum } \\
(\%)\end{array}$ & $\begin{array}{c}\text { Maximum } \\
\text { possible } \\
(\%)\end{array}$ & $\begin{array}{c}\text { Optimum } \\
(\%)\end{array}$ & $\begin{array}{c}\text { Maximum } \\
\text { possible } \\
(\%)\end{array}$ & $\begin{array}{c}\text { Optimum } \\
(\%)\end{array}$ & $\begin{array}{c}\text { Maximum } \\
\text { possible } \\
(\%)\end{array}$ & $\begin{array}{c}\text { Optimum } \\
(\%)\end{array}$ & $\begin{array}{c}\text { Maximum } \\
\text { possible } \\
(\%)\end{array}$ \\
\hline Lodwar & $44 \%$ & 52 & 40 & 45 & 21 & 30 & 37 & 41 \\
Nyeri & 5 & 17 & 3 & 8 & 2 & 3 & 2 & 8 \\
Mombasa & 8 & 22 & 3 & 10 & 2 & 4 & 4 & 14 \\
\hline
\end{tabular}

late to reduced environmental degradation risks as well as exposures to health hazards associated with firewood use.

\subsection{Recommendations}

1) The knowledge on the stochastic behaviour of the solar energy resource as revealed in this study would be useful to government policy makers for purposes of planning for its effective and efficient tapping.

2) With regard to the relevant technologies, constructing systems using cheap and locally available materials and designs which may easily be maintained by even semi-skilled personnel will make the systems more attractive to the rural folk who currently are faced with a multitude of economic challenges.

3) A detailed evaluation of the implications of switching from traditional firewood to solar technology is required in rural households of Kenya. This is because fire also has a multipurpose lighting and social function.

4) A major issue which must be addressed with regard to solar technology is the relevancy of the technology to rural women. This is because practically everywhere, women, and not men, do the cooking and therefore, such technologies directly affect them. Consequently, a general requirement for all measures is that the technology contributes directly towards improving the situation of women in their roles as housewives/mothers and towards advancing their social self-determination.

\section{Acknowledgements}

The author would like to thank the Kenya Meteorological Department for availing the global solar radiation data used in this study. Further gratitude goes to my fellow researchers at the Institute for Meteorological Training and Research for their constant encouragement as I developed this paper. Last but not least, comments and suggestions as provided by the anonymous reviewer(s) are greatly appreciated as they considerably improved the manuscript.

\section{References}

[1] World Meteorological Organization (WMO) (1981) Meteorological Aspects of the Utilization of Solar Radiation as an Energy Source. WMO Technical Note No. 172, Geneva.

[2] Government of Kenya (GoK) (2015) The Second National Communication to the UNFCCC. 212 p. 
[3] Government of Kenya (GoK) (2010) The National Climate Change Response Strategy. 97 p.

[4] Smith, K.R. (1993) The Health Impact of Cookstove Smoke in Africa. In: Oesterdiekhoff, P., Ed., African Development Perspectives Yearbook, Vol. 3, Universitat Bremen, Bremen.

[5] Smith, K.R. (1987) Biofuels, Air Pollution and Health. Plenum, New York.

[6] Obasi, G.O.P. and Rao, N.N.P. (1976) Solar Energy Resources in Kenya. Proceedings of East African Symposium on Energy Resources in Eastern Africa, Arusha, Tanzania, 30th August-3rd September, 1976.

[7] Okoola, R.E. (1982) Solar Power Potential in Kenya. An IMTR Research Publication Report No. 1/82, 1-24.

[8] Kuhnke, K., Reuber, M. and Schwefel, D. (1990) Solar Cookers in the Third World. Vieweg + Teubner Verlag, Berlin.

[9] Thomas, B.J., Kelly, H., Amulya, K.N. and Williams, R. (1993) Renewable Energy. Sources for Fuels and Electricity, Island Press, Washington DC.

[10] Gupta, V.K. and Duckstein, L. (1975) A Stochastic Analysis of Extreme Droughts. Water Resources Research, 11, 221-228. https://doi.org/10.1029/WR011i002p00221

[11] Sen, Z. (1980) Statistical Analysis of Hydrological Critical Droughts. Journal of the Hydraulics Division, 106, 99-115.

[12] Todorovic, P. and Woolhiser, D.A. (1975) A Stochastic Model of $n$ Day Precipitation. Journal of Applied Meteorology, 14, 17-24. https://doi.org/10.1175/1520-0450(1975)014<0017:ASMODP >2.0.CO;2

[13] Sen, Z. (1977) Run Sums of Annual Flow Series. Journal of Hydrology, 35, 311-324.

[14] Solar Cookers International (SCI) (1999) Timely Plan for Financing Solar Cooker Projects. Solar Cookers Review, 5, 4-5.

\section{Submit or recommend next manuscript to SCIRP and we will provide best} service for you:

Accepting pre-submission inquiries through Email, Facebook, LinkedIn, Twitter, etc. A wide selection of journals (inclusive of 9 subjects, more than 200 journals) Providing 24-hour high-quality service User-friendly online submission system Fair and swift peer-review system Efficient typesetting and proofreading procedure Display of the result of downloads and visits, as well as the number of cited articles Maximum dissemination of your research work

Submit your manuscript at: http://papersubmission.scirp.org/

Or contact gep@scirp.org 